\title{
AVALIAÇÃO DO DESEMPENHO DE DOIS SISTEMAS MODULARES NO TRATAMENTO ANAERÓBIO DE ESGOTOS EM COMUNIDADES RURAIS ${ }^{1}$
}

\author{
ANTÔNIO JAVAREZ JÚNIOR ${ }^{2}$, DURVAL R. DE PAULA JÚNIOR ${ }^{3}$, \\ JONATHAN GAZZOLA ${ }^{4}$
}

\begin{abstract}
RESUMO: Este trabalho apresenta uma alternativa de baixo custo e fácil instalação para o tratamento de esgotos de pequenas comunidades. O experimento foi desenvolvido no Campo Experimental da Faculdade de Engenharia Agrícola (FEAGRI/UNICAMP). O volume total de esgoto gerado na FEAGRI é de cerca de $20 \mathrm{~m}^{3} \mathrm{dia}^{-1}$, sendo metade desse tratado pelos sistemas modulares. O sistema da linha (A) é constituído por um reator UASB (Upflow Anaerobic Sludge Blanket), seguido de dois filtros anaeróbios e o outro sistema, linha (B), é constituído por um reator tipo RAC (Reator Anaeróbio Compartimentado), seguido de dois filtros anaeróbios (FA). Os sistemas foram operados de dezembro de 2002 a fevereiro de 2004, totalizando 30 coletas de amostras. Observou-se que, de maneira geral, o desempenho dos sistemas foram similares e com resultados satisfatórios. As eficiências médias de remoção de Sólidos Sedimentáveis, Sólidos Suspensos Totais e DQO, observadas no sistema modular da Linha (A), foram, respectivamente, 99,58\%; 94,33\% e 67,30\%. O sistema modular da Linha (B) apresentou remoção de 99,49\%; 93,34\% e 70,45\% para os mesmos parâmetros. Os sistemas modulares mostraram-se adequados e viáveis para promover o tratamento sanitário do esgoto produzido em pequenas comunidades.
\end{abstract}

PALAVRAS-CHAVE: sistemas modulares, reator anaeróbio, tratamento de esgoto.

\section{PERFORMANCE EVALUATION OF TWO MODULAR SYSTEMS FOR WASTEWATER TREATMENT IN RURAL COMMUNITIES}

\begin{abstract}
This research work introduces an alternative of low cost and easily installable system for treatment of wastewater applied to small communities. These experiments were developed at Experimental Field of Agricultural Engineering College (AEC/UNICAMP). The total volume produced at AEC is $20 \mathrm{~m}^{3}$ day $^{-1}$, and half part was treated by modular systems. The first system line (A) is composed by an UASB reactor (Upflow Anaerobic Sludge Blanket) followed by two Anaerobic Filters and the second system (B) line is composed by a kind of reactor called CAR (Compartmented Anaerobic Reactor) and it is followed by two Anaerobic filters too. Both systems were handled from December of 2002 through February of 2004 totalizing 30 sample collections. It was concluded under comparation that both system performances were similar and obtained satisfactory results. Medium grades of efficiency in remotion of sedimentable solids, total suspended solids and CDO (Chemical demand of oxygen) obtained in modular system (A) were 99.58\%; $94.33 \%$ and $67.30 \%$ respectively. Modular system (B) showed a remotion of $99.49 \%$; $93.34 \%$ and $70.45 \%$ to the same evaluation parameters. Both modular systems demonstrated adequate and viable to promote a sanitary treatment of wastewater produced in small communities.
\end{abstract}

KEYWORDS: modular systems, anaerobic reactor, wastewater treatment.

\footnotetext{
${ }^{1}$ Extraído da tese de doutorado do primeiro autor.

${ }^{2}$ Eng $^{\mathrm{o}}$ Agrônomo, Doutor em Engenharia Agrícola, Profissional de Pesquisa, Faculdade de Engenharia Agrícola, UNICAMP, Campinas - SP, Fone: (0XX19) 3788.1126, ajjunior@agr.unicamp.br

${ }^{3}$ Eng $^{\mathrm{o}}$ Civil, Professor Associado, FEAGRI, UNICAMP, Campinas - SP, Fone: (0XX19) 3788-1035, durval@agr.unicamp.br

${ }^{4}$ Graduando em Engenharia Agrícola, Faculdade de Engenharia Agrícola, UNICAMP, Campinas - SP.

Recebido pelo Conselho Editorial em: 20-11-2006
}

Aprovado pelo Conselho Editorial em: 27-9-2007 


\section{INTRODUÇÃO}

O saneamento, além da sua grande importância para a preservação dos recursos naturais, representa ação preventiva eficaz para a melhoria do bem-estar e da qualidade de vida da população nas questões relacionadas à saúde pública. Entretanto, ainda são escassos os recursos para os investimentos necessários às diversas áreas, inclusive àquelas que atendem à população, especialmente a de baixa renda.

Apesar da falta de estudos científicos sobre o assunto, na área rural, a contaminação do solo e das águas de superfície e subterrâneas decorrentes do não-tratamento das águas residuárias domiciliares e das águas residuárias geradas em outras atividades zootécnicas já é uma realidade que preocupa diversos setores da sociedade, gerando a necessidade de alternativas para o seu tratamento de forma descentralizada e por meio de sistemas com baixo custo de instalação e manutenção e, ainda, de fácil operação.

As ações efetivas para a resolução desse problema são demoradas, pois dependem da construção de sistemas de tratamento de águas residuárias que são onerosos e nem sempre valorizados pela população. Há, portanto, a real necessidade de estudos na área de saneamento visando à implantação de sistemas economicamente viáveis, tanto na construção como na operação e manutenção, e que permitam investimentos em curto prazo.

Verificou-se, durante os últimos anos, uma verdadeira revolução nos conceitos concernentes ao tratamento de águas residuárias. Nesse período, além de ampliar e valorizar a aplicabilidade do processo anaeróbio, também foi aumentado significativamente o número de alternativas para concepção física das unidades para conversões biológicas (FORESTI et al., 1999).

O crescimento e o desenvolvimento da tecnologia de tratamento de esgotos por via anaeróbia abriram novos caminhos para a área de tratamento de esgotos no Brasil, ocupando posição de destaque no saneamento (ARAÚJO et al., 2000). A valorização dessa tecnologia deve-se as suas características favoráveis, dentre as quais a baixa produção de sólidos, o baixo custo e a simplicidade operacional, aliado ao clima e às condições ambientais propícias do Brasil, que oferecem (o ano todo) temperatura relativamente elevada, que aceleram o mecanismo de tratamento.

Os baixos custos de instalação, manutenção e operação das unidades, juntamente com satisfatória eficiência de remoção, viabilizaram a implantação de reatores UASB (Upflow Anaerobic Sludge Blanket) para esgoto sanitário. Outras características que os tornaram apropriados, foram a simplicidade de construção e a não-necessidade de material de enchimento e equipamentos eletromecânicos. Dessa forma, o reator UASB constituiu-se num dos sistemas de tratamento anaeróbio que mais se desenvolveram ultimamente (ARAÚJO et al., 2000).

Segundo CHERNICHARO et al. (1999), esse reator representa grande avanço na aplicação da tecnologia anaeróbia para o tratamento direto de águas residuárias, sejam de natureza simples sejam complexas, de baixa ou de alta concentração, solúveis ou com material particulado. São sistemas compactos com baixa demanda de área, baixa produção de lodo, baixo consumo de energia, satisfatória eficiência de remoção de DBO (demanda bioquímica de oxigênio) e de DQO (demanda química de oxigênio) - da ordem de $65 \%$ a $75 \%$, possibilidade de rápido reinício (mesmo após longas paralisações), baixa produção de lodo excedente e boa desidratabilidade do lodo.

O Reator Anaeróbio Compartimentado (RAC) tem sido estudado com o objetivo de reduzir ainda mais os custos de implantação e de operação proporcionados pelos reatores UASB. VALENTIM (1999) obteve eficiências na faixa de 17 a $69 \%$ para remoção de DQO e na faixa de 58 a 92\% para sólidos suspensos totais (SST), operando com Tempos de Detenção Hidráulica (TDH) na faixa de 12 a 24 horas.

AISSE et al. (2000) apresentaram estudo comparativo entre esses reatores com esgotos domésticos, constatando que as eficiências na remoção da DQO, dos STs (sólidos totais) e do SST 
do reator UASB foram superiores às do RAC. Os reatores foram operados com TDH de 24 horas, sendo obtidos, respectivamente, valores de $70 \%, 39 \%$ e $73 \%$ para o UASB e $58 \%, 33 \%$ e $61 \%$ para o RAC.

Dentro desse contexto, propõe-se, neste trabalho, avaliar o desempenho de modelos de tratamento de esgoto por meio de sistemas modulares alternativos, promovendo o aprimoramento dos sistemas de tratamento de esgotos sanitários.

\section{MATERIAL E MÉTODOS}

A Faculdade de Engenharia Agrícola, da Universidade Estadual de Campinas (FEAGRI/UNICAMP), é servida pela água da Companhia de Abastecimento de Água de Campinas (SANASA) e também por poços artesianos localizados na Universidade, sendo utilizada para o abastecimento dos laboratórios, dos prédios da área administrativa e das salas de aula, cuja área construída é de $4.100 \mathrm{~m}^{2}$.

A Faculdade possui uma população média diária, em período de aulas, de 250 pessoas, resultando em vazão média estimada de cerca de $20 \mathrm{~m}^{3}$ de esgoto por dia. As variações da vazão em um sistema de esgoto ocorrem em função dos costumes e peculiaridades dos habitantes. Devido às condições impostas pelo funcionamento da Faculdade, principalmente com relação aos finais de semana e mesmo durante o período letivo, há grande variação na vazão do esgoto (VALENTIM, 1999). A caracterização do esgoto da FEAGRI, composto de dejetos domésticos e sanitários dos prédios de aula, da área administrativa e dos laboratórios, está ilustrada na Tabela 1.

TABELA 1. Caracterização do esgoto da FEAGRI/UNICAMP.

\begin{tabular}{|c|c|c|}
\hline Parâmetros de Controle & Valores Típicos & Mínimos e Máximos \\
\hline $\begin{array}{l}\text { Sólidos suspensos }\left(\mathrm{mg} \mathrm{L}^{-1}\right) \\
\text {. }\end{array}$ & 84,00 & $10-700$ \\
\hline Sólidos sedimentáveis $\left(\mathrm{mL} \mathrm{L}^{-1}\right)$ & 44,00 & $40-70$ \\
\hline $\mathrm{DQO}\left(\mathrm{mg} \mathrm{O}_{2} \mathrm{~L}^{-1}\right)$ & 316,00 & $125-450$ \\
\hline Coliformes totais (NMP $100 \mathrm{~mL}^{-1}$ ) & $2,41910^{6}$ & \\
\hline Nitrogênio total $\left(\mathrm{mg} \mathrm{L}^{-1}\right)$ & 42,50 & \\
\hline Fósforo $\left(\mathrm{mg} \mathrm{L}^{-1}\right)$ & 8,31 & \\
\hline $\mathrm{pH}$ & 7,93 & $7,20-8,10$ \\
\hline
\end{tabular}

Fonte: VALENTIM (1999)

Cerca de $10 \mathrm{~m}^{3}$ de esgoto, metade do volume gerado diariamente na Faculdade, é tratado por dois sistemas modulares, objeto de estudo deste trabalho, os quais foram implantados no Campo Experimental da FEAGRI, como foi apresentado por PAULA JÚNIOR et al. (2000), JAVAREZ JÚNIOR \& PAULA JÚNIOR (2003) e JAVAREZ JÚNIOR (2005), e que operam em condições reais de vazão. A representação esquemática dos dois sistemas, constituídos por reatores UASB ou RAC e por dois Filtros Anaeróbios (FA), é mostrada, respectivamente, nas Figuras 1 e 2.

Foram utilizados materiais facilmente encontrados comercialmente, sendo considerado seu baixo custo e que seja de fácil instalação, como, por exemplo, reservatórios de fibra de vidro e tubos e conexões de PVC, adaptados para comunidades que carecem de soluções modulares de fácil acesso e baixo custo.

Na montagem dos reatores anaeróbios, por serem as caixas de fibra de vidro de configuração circular e, ainda, no intuito de manter o fluxo do esgoto uniformemente distribuído dentro desses, foram construídas entradas em forma de estrela, colocadas no fundo das caixas. Na montagem dos filtros anaeróbios, além da referida entrada do afluente, utilizou-se de anéis plásticos ("Orings") como meio de suporte para o biofilme. 


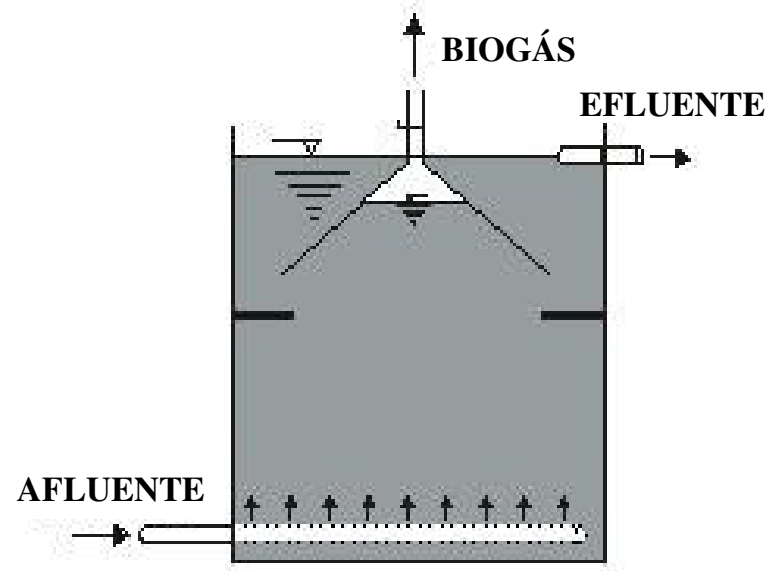

REATOR UASB

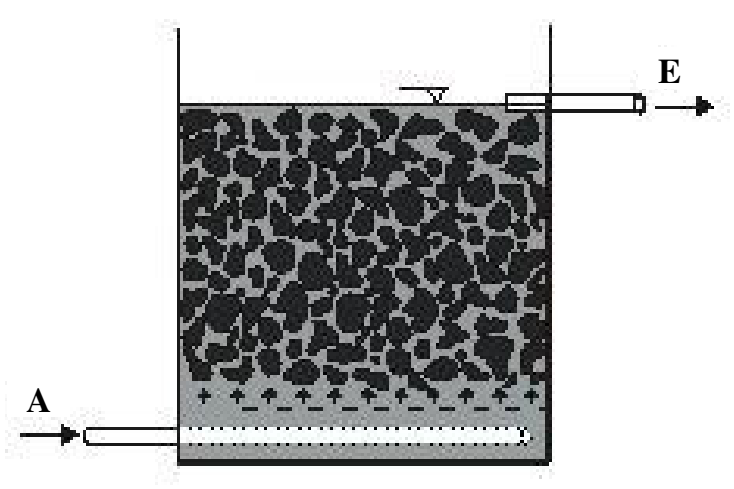

FILTRO ANAERÓBIO

FIGURA 1. Diagrama do Reator UASB e do filtro anaeróbio.

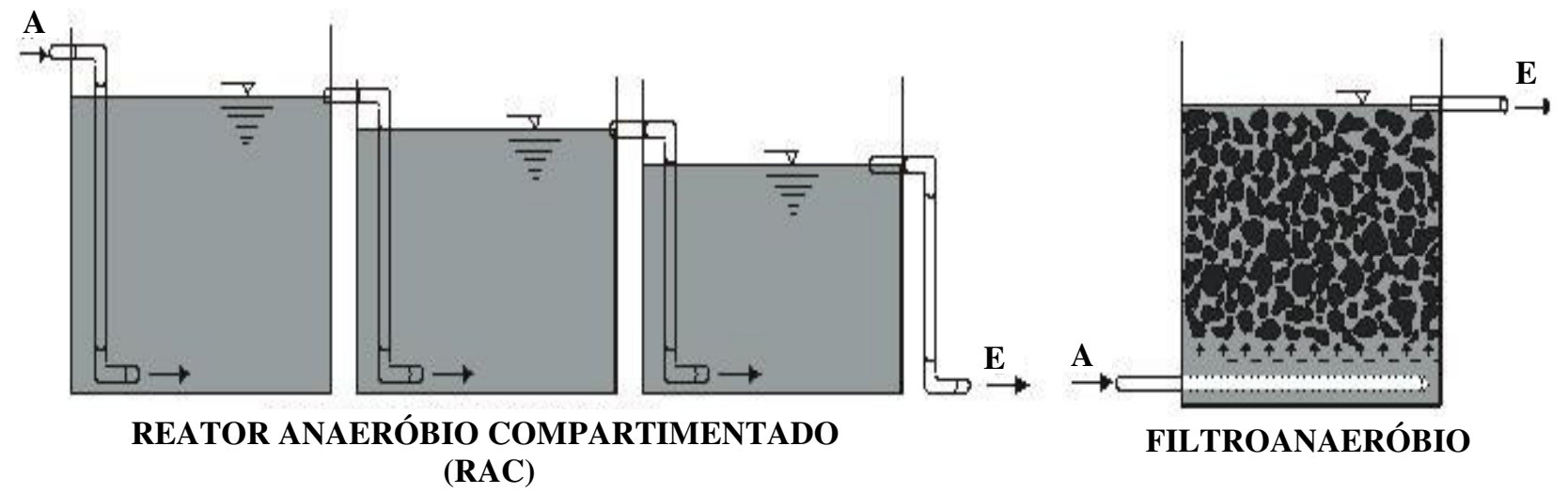

FIGURA 2. Diagrama do Reator RAC e do filtro anaeróbio.

Do volume de esgoto gerado diariamente na FEAGRI, cada sistema modular de tratamento desse projeto-piloto, em escala real e operado em condições reais de sazonalidade e sobrecarga do sistema, tratou vazão de cerca de $5.000 \mathrm{~L} \mathrm{dia}^{-1}$, com TDH de cerca de 24 horas para cada reator (UASB e RAC) e cerca de 24 horas nos FAs. Os sistemas modulares das Linhas (A) e (B) foram operados, portanto, com TDH de 48 horas, totalizando volume útil de cerca de $10.000 \mathrm{~L}$ para cada sistema.

O volume da linha de fluxo (A) é representado pelo somatório do volume do reator UASB $(5.000 \mathrm{~L})$ com o volume útil de dois FAs (cerca de $5.000 \mathrm{~L}$, no total). No sistema modular da linha de fluxo (B), o volume útil é constituído pelo somatório do volume do RAC, constituído de três reservatórios com capacidade de 2.500, 1.500 e $1.000 \mathrm{~L}$, com o volume útil de dois FAs (cerca de $5.000 \mathrm{~L}$, no total).

Os dados utilizados baseiam-se no monitoramento dos sistemas, com frequiência de coleta de amostras de cerca de 15 dias, no período de dezembro de 2002 a fevereiro de 2004, totalizando 30 coletas de amostras. Foram coletadas amostras no afluente (A1 e B1) e nas saídas de cada reator, UASB (A2) e RAC (B2), e dos filtros anaeróbios (A3 e B3).

O desempenho de cada sistema foi avaliado por meio de análise estatística descritiva das determinações de Sólidos Sedimentáveis (SSed), Sólidos Suspensos Totais (SST) e Demanda Química de Oxigênio (DQO). A determinação das eficiências de remoção foi calculada considerando-se apenas os valores médios obtidos em cada parâmetro analisado, durante os 450 dias em operação. As análises foram efetuadas de acordo com o especificado no Standard Methods (AWW/APHA/WPCF, 1995). 


\section{RESULTADOS E DISCUSSÃO}

As concentrações médias de SSed, SST e DQO dos sistemas modulares da Linha (A) e da Linha (B), bem como seus valores de coeficiente de variação (C.V.\%) e desvio-padrão ( $\gamma$ ), estão mostrados nas Tabelas 2 e 3, respectivamente. O desempenho temporal dos sistemas modulares das Linhas (A) e (B), bem como dos reatores UASB e RAC isoladamente, está apresentado nas Figuras 3 e 4 para as concentrações de SST, e nas Figuras 5 e 6 para os valores de DQO. Na Tabela 4, estão apresentadas as eficiências médias de remoção de SSed, SST, DQO de cada sistema modular.

TABELA 2. Concentrações de SSed, SST e DQO obtidas no sistema modular da Linha (A).

\begin{tabular}{cccrrrrrrr}
\hline Estatística & \multicolumn{3}{c}{ SSed $\left(\mathrm{mL} \mathrm{L}^{-1}\right)$} & \multicolumn{3}{c}{ SST $\left(\mathrm{mg} \mathrm{L}^{-1}\right)$} & \multicolumn{3}{c}{ DQO $\left(\mathrm{mg} \mathrm{L}^{-1}\right)$} \\
\cline { 2 - 10 } Descritiva & Afluente & UASB & FA & Afluente & UASB & FA & Afluente & UASB & FA \\
\hline Mínimo & 1,20 & 0,1 & 0,1 & 100,0 & 10,0 & 1,7 & 44,8 & 14,8 & 8,0 \\
Média & 33,40 & 0,5 & 0,1 & 557,3 & 61,7 & 31,6 & 327,7 & 158,0 & 107,2 \\
Máximo & 75,00 & 1,5 & 0,4 & $1.646,7$ & 220,0 & 160,0 & 976,0 & 860,6 & 843,4 \\
\hline$\gamma$ & 19,9 & 0,3 & 0,1 & 456,7 & 51,3 & 30,8 & 263,3 & 164,4 & 161,3 \\
C.V.\% & 59,6 & 63,6 & 51,5 & 81,9 & 83,3 & 97,3 & 80,3 & 104,1 & 150,5 \\
\hline
\end{tabular}

$\gamma$ - desvio-padrão; C.V.\% - coeficiente de variação.

TABELA 3. Concentrações de SSed, SST e DQO obtidas no sistema modular da Linha (B).

\begin{tabular}{cccrrrrrrr}
\hline Estatística & \multicolumn{3}{c}{ SSed $\left(\mathrm{mL} \mathrm{L}^{-1}\right)$} & \multicolumn{3}{c}{ SST $\left(\mathrm{mg} \mathrm{L}^{-1}\right)$} & \multicolumn{3}{c}{ DQO $\left(\mathrm{mg} \mathrm{L}^{-1}\right)$} \\
\cline { 2 - 9 } Descritiva & Afluente & \multicolumn{1}{c}{ RAC } & FA & Afluente & RAC & FA & Afluente & RAC & FA \\
\hline Mínimo & 6,0 & 0,1 & 0,0 & 91,7 & 8,3 & 5,0 & 44,5 & 16,1 & 17,3 \\
Média & 39,0 & 0,3 & 0,2 & 594,4 & 56,1 & 39,6 & 326,6 & 131,8 & 96,5 \\
Máximo & 100,0 & 0,8 & 0,6 & $1.730,0$ & 225,0 & 215,0 & 958,7 & 780,3 & 837,6 \\
\hline$\gamma$ & 26,4 & 0,2 & 0,1 & 536,8 & 51,5 & 50,0 & 246,6 & 153,5 & 156,4 \\
C.V.\% & 67,8 & 59,4 & 70,1 & 90,3 & 91,9 & 126,2 & 75,5 & 116,5 & 162,1 \\
\hline
\end{tabular}

$\gamma$ - desvio-padrão; C.V.\% - coeficiente de variação.

Comparando-se os valores do afluente das Tabelas 2 e 3 com os valores de caracterização do esgoto da FEAGRI/UNICAMP (Tabela 1), apresentados por VALENTIM (1999), observa-se que os valores médios, em cada parâmetro analisado, ficaram dentro da faixa de valores máximos e mínimos obtido pelo autor. Contudo, verificou-se que houve maior variação nos valores máximos e mínimos obtidos no período deste ensaio. Essa diferença entre os valores do afluente pode ser explicada, em parte, pelas condições impostas pelo funcionamento da Faculdade, principalmente com relação aos finais de semana e mesmo durante os períodos letivos, havendo grande variação na vazão do esgoto, principalmente nos períodos de férias.

O presente ensaio teve duração de 450 dias com os sistemas modulares em operação, realizando-se as coletas de amostra, independentemente do período letivo. O período experimental realizado por VALENTIM (1999) foi de apenas 4,5 meses, a partir de 15 de setembro de 1998, sendo as amostras do afluente coletadas no final do ensaio, durante cerca de 90 dias.

Analisando o valor médio de DQO no afluente, verifica-se que é inferior à faixa de 450 a $800 \mathrm{mg} \mathrm{O}_{2} \mathrm{~L}^{-1}$, descrita por SPERLING (1995) como sendo a concentração característica para DQO de esgotos domésticos. Experimento realizado anteriormente por MAZZOLA (2003) também apresentou valores relativamente baixos de DQO no afluente (entre 93 e $508 \mathrm{mg} \mathrm{de}_{2} \mathrm{~L}^{-1}$ ).

Os valores de C.V.\% dos dados foram elevados (acima de 50\%) em todos os pontos amostrados; esses valores eram esperados na entrada dos sistemas, pois a vazão do esgoto da Faculdade apresenta sazonalidade. As maiores variações foram observadas nas concentrações obtidas no efluente dos FAs. Verificou-se, ainda, que os maiores valores de C.V.\% foram obtidos 
na concentração de DQO, cujos desvios-padrão nos efluentes dos reatores foram superiores aos seus valores médios.

Parte dessa alta variação nos valores médios de SSed, SST e DQO pode ser atribuída aos eventuais picos de vazão, inerentes às características do esgoto da FEAGRI e aos problemas com as caixas de areia e distribuição, inclusive com alguns entupimentos na entrada. Foi constatado, também, que parte das galerias pluviais possui ligação com a rede coletora de esgoto, propiciando, principalmente no verão, elevação abrupta e pontual na vazão do afluente e diminuição no TDH dos sistemas modulares de tratamento, podendo ter ocasionado arraste do lodo dos reatores.

VALENTIM (1999) e MAZZOLA (2003) também obtiveram, durante o período de partida de seus sistemas, valores de SST e, principalmente, DQO mais elevados no efluente final, comparados com os pontos intermediários ou mesmo no afluente. Os autores afirmam que os sistemas estavam sofrendo possível estabilização do ponto de vista biológico, indicando que o provável acúmulo de sólidos ocorrido no interior dos mesmos, durante as primeiras semanas de funcionamento, estava em processo de degradação e contribuindo para o aumento dos valores da DQO em seus efluentes.

A variação nos valores de SSed, SST e DQO dos efluentes finais das Linhas (A) e (B), obtidos no início de operação (período de partida) dos sistemas modulares de tratamento, pode ter sido responsável por aumentar o C.V.\% de suas concentrações, com valores menores após a estabilização dos reatores.

Comparando-se os valores médios dos parâmetros estudados entre os sistemas modulares de tratamento, verificou-se que houve pequena diferença nas concentrações SSed, SST e DQO, principalmente no efluente dos FAs. As maiores diferenças foram observadas entre as concentrações médias obtidas no efluente do reator principal de cada sistema, UASB na Linha (A) e RAC na Linha (B). Apesar de os valores médios de SSed, SST e DQO na entrada (afluente) no sistema da Linha (B) serem superiores aos da Linha (A), as concentrações médias observadas na saída (efluente) do RAC foram menores, indicando desempenho ligeiramente melhor.

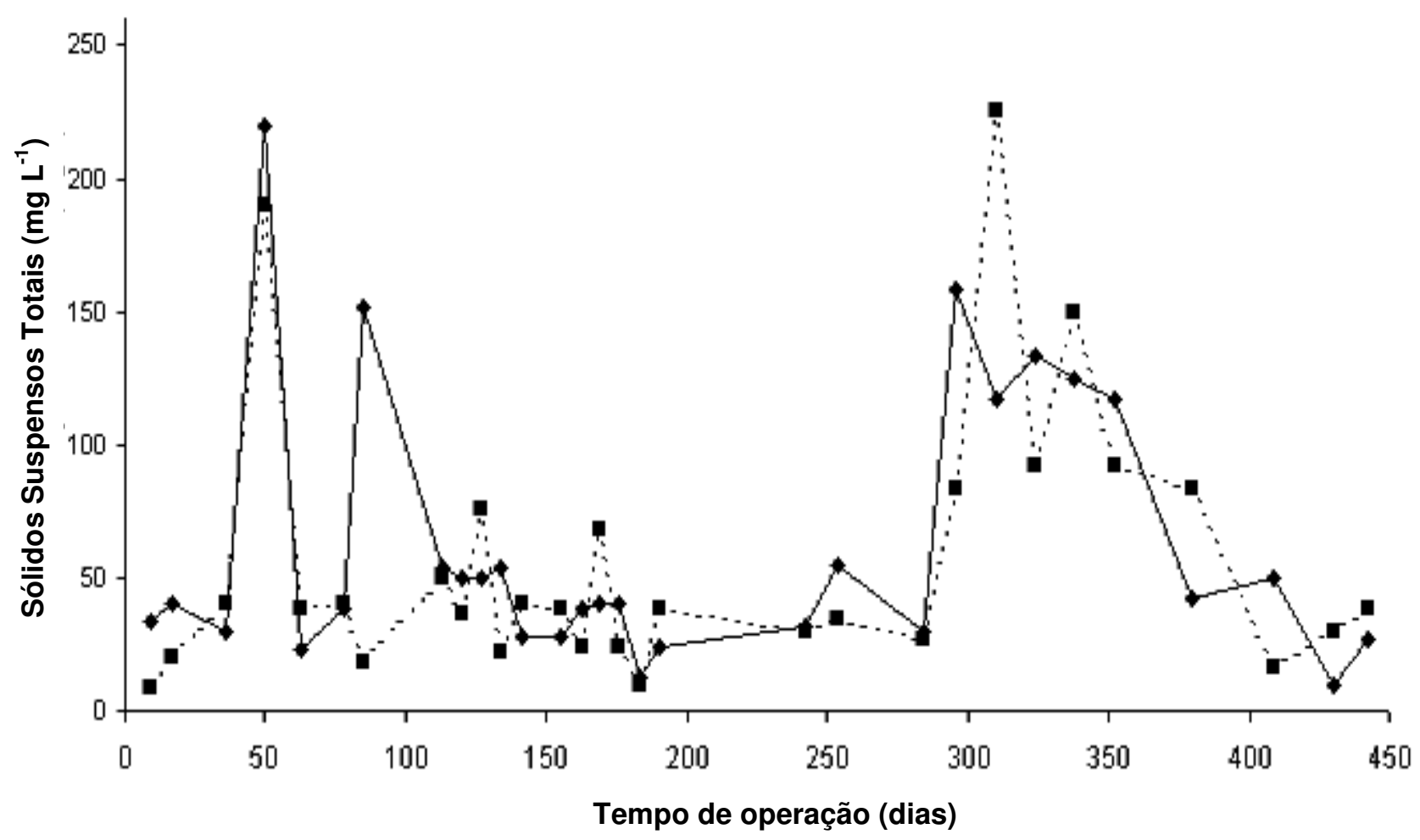

FIGURA 3. Evolução temporal de sólidos suspensos totais - SST, nos efluentes dos reatores UASB e RAC. 


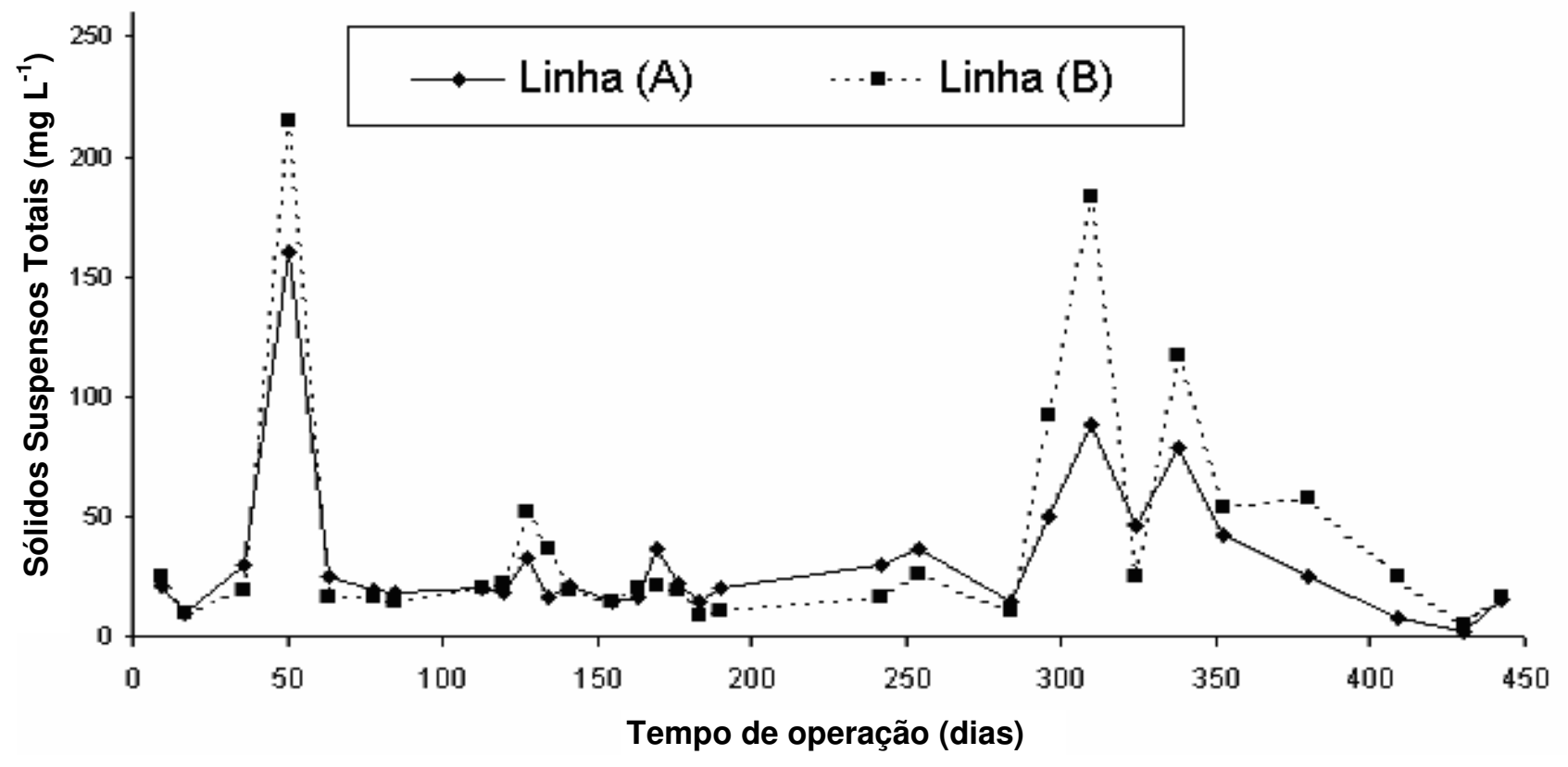

FIGURA 4. Evolução temporal de sólidos suspensos totais - SST, nos efluentes finais das Linhas A (UASB-FA) e B (RAC-FA).

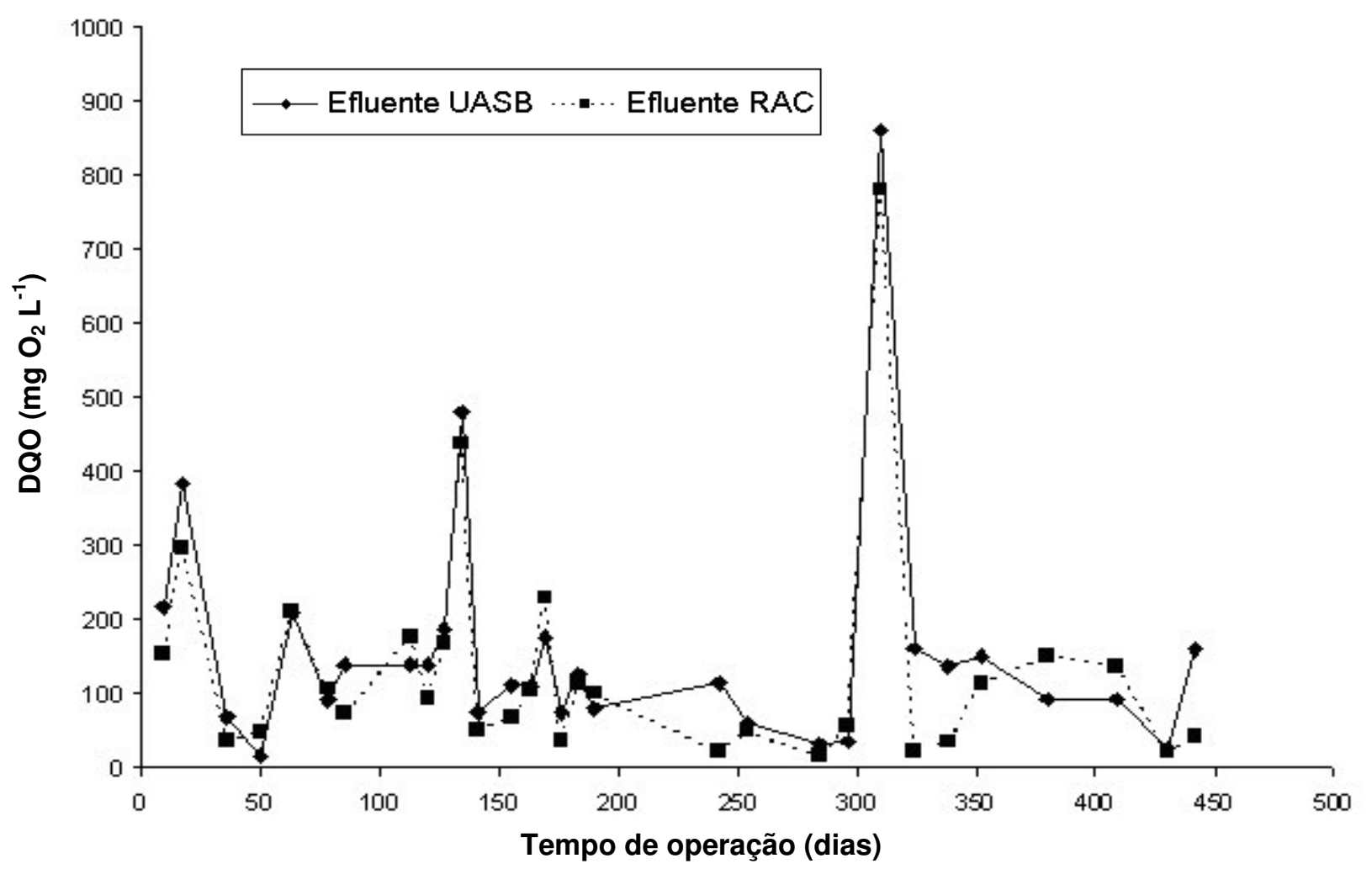

FIGURA 5. Evolução temporal da DQO, nos efluentes dos reatores UASB e RAC. 


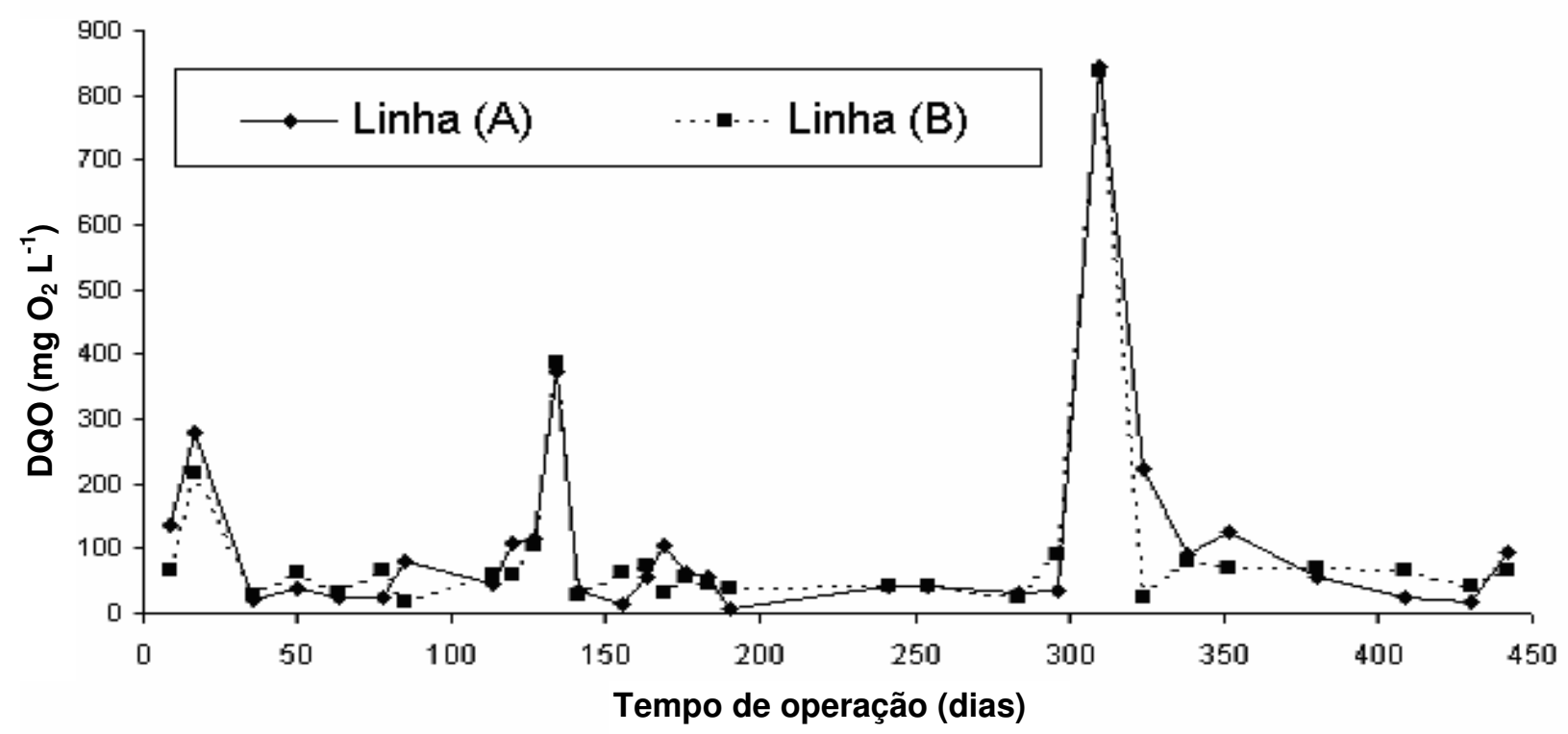

FIGURA 6. Evolução temporal da DQO nos efluentes finais da Linha A (UASB-FA) e Linha B (RAC-FA).

As menores médias no RAC devem-se, provavelmente, a sua constituição em compartimentos (câmaras), promovendo maior contato do esgoto com os microrganismos e, também, atenuando a perda de sólidos (lodo), caso sejam verificadas grandes variações e picos excessivos da vazão afluente.

É provável que a perda de sólidos seja maior no reator UASB, apesar de que uma das condições fundamentais, em cima da qual se fundamenta sua capacidade de acomodar altas cargas, é a sua característica de alta retenção de lodo, desde que haja suficiente contato entre a biomassa e o esgoto. No entanto, essa capacidade de armazenamento do reator esgota-se gradativamente, podendo levar à descarga involuntária de lodo no efluente.

Observa-se, na Tabela 4, que, de maneira geral, os desempenhos dos sistemas foram satisfatórios. As eficiências médias de remoção, calculadas a partir dos valores médios, foram de 99,58\%; 94,33\% e 67,30 para SSed, SST e DQO, respectivamente, observados no sistema modular da Linha (A), e de 99,49\%; 93,34\% e 70,45\% para SSed, SST e DQO no sistema modular da Linha (B), respectivamente.

TABELA 4. Eficiências médias de remoção de SSed, SST e DQO (\%).

\begin{tabular}{ccccccc}
\hline \multirow{2}{*}{ Parâmetro } & \multicolumn{3}{c}{ Linha A } & \multicolumn{3}{c}{ Linha B } \\
\cline { 2 - 7 } & UASB & FA & Sistema & RAC & FA & Sistema \\
\hline SSed & 98,49 & 71,83 & 99,58 & 99,13 & 41,76 & 99,49 \\
SST & 88,94 & 48,74 & 94,33 & 90,57 & 29,40 & 93,34 \\
DQO & 51,80 & 32,16 & 67,30 & 59,63 & 26,80 & 70,45 \\
\hline
\end{tabular}

O desempenho dos sistemas modulares nos resultados de remoção de SSed é atribuído ao princípio de funcionamento dos reatores UASB e RAC, os quais funcionam como decantadores, promovendo grande remoção de sólidos sedimentáveis. Esse comportamento também foi observado em reatores anaeróbios por HAANDEL \& LETTINGA (1994) e MAZZOLA (2003).

Comparando-se a eficiência de remoção de DQO do UASB, ou mesmo da Linha (A), com os resultados obtidos por MORAIS et al. (2001), verifica-se que seu desempenho foi inferior, tendo os autores constatado eficiências superiores a 70\%. Ao se comparar o desempenho obtido pelo RAC, verifica-se que foi ligeiramente superior ao apresentado por VALENTIM (1999), que foi de $61 \%$. 
Observa-se, na Tabela 4, que os valores médios de remoção do RAC foram ligeiramente superiores aos obtidos no UASB, em contraste com os resultados obtidos por AISSE et al. (2000), que apresentaram estudo comparativo entre esses reatores, constatando que as eficiências na remoção de DQO e de SST do reator UASB foram superiores às obtidas no RAC. Foram obtidos valores de $70 \%$ e $73 \%$ para o UASB e $58 \%$ e $61 \%$ para o RAC.

Constatou-se, portanto, que o desempenho dos FAs na remoção de SSed, SST e DQO foi influenciado pela eficiência de remoção apresentada pelos reatores UASB e RAC, atuando como complemento no tratamento do esgoto, principalmente durante períodos de sobrecarga dos sistemas.

De modo geral, a eficiência dos FAs na remoção dos parâmetros avaliados foi superior na Linha (A), demonstrando que o RAC obteve melhor eficiência, mantendo seu desempenho mais uniforme durante o período estudado. Esse desempenho deveu-se, provavelmente, à constituição de cada reator, e a presença de três câmaras no RAC promoveu maior remoção dos sólidos e da DQO.

\section{CONCLUSÕES}

Os sistemas modulares, combinando diferentes reatores (UASB e RAC) com Filtros Anaeróbios, foram eficientes no tratamento de esgoto, reduzindo significativamente o material orgânico no efluente. Portanto, os sistemas modulares constituíram-se em uma forma adequada e viável de promover o tratamento sanitário do esgoto produzido em pequenas comunidades.

\section{AGRADECIMENTO}

Os autores agradecem à Fundação de Amparo à Pesquisa do Estado de São Paulo (FAPESP), financiadora do projeto.

\section{REFERÊNCIAS}

AISSE, M.M.; LOBATO, M.B.; BONA, A.; GARBOSSA, L.H.P. Estudo comparativo do reator UASB e do reator anaeróbio compartimentado seqüencial no tratamento de esgoto sanitário. In: CONGRESO INTERAMERICANO DE INGENIERIA SANITARIA Y AMBIENTAL, 27., 2000, Porto Alegre. Anais... Rio de Janeiro: ABES, 2000. p.1-9.

APHA/AWWA/WPCF. Standard methods for the examination of water and wastewater. $19^{\text {th }}$ ed. Washington: American Public Health Association, 1995. 1.134 p.

ARAÚJO, G.C.; CHERNICHARO, C.A.; SPERLING, M. Von. Análise da remoção de matéria orgânica e sólidos ao longo de um sistema de aplicação de esgotos no solo tratando efluentes de reatores UASB. In: SILUBESA-SIMPÓSIO LUSO-BRASILEIRO DE ENGENHARIA SANITÁRIA E AMBIENTAL, 9., 2000, Porto Seguro. Anais... Associação Brasileira de Engenharia Sanitária e Ambiental, 2000. p.1.098-106.

CHERNICHARO, C.A.L.; HAANDEL, A. Van; AISSE, M.M.; CAVALCANTI, P.F.F. Reatores anaeróbios de manta de lodo, In: CAMPOS, J.R. (Coord.) Tratamento de esgotos sanitários por processo anaeróbio e disposição controlada no solo. Rio de Janeiro: ABES/ PROSAB, 1999. p.155-98.

FORESTI, E.; FLORÊNCIO, L.; HAANDEL, A. Van; ZAIAT, M.; CAVALCANTI, P.F.F. Fundamentos do tratamento anaeróbio, In: CAMPOS, J.R. (Coord.) Tratamento de esgotos sanitários por processo anaeróbio e disposição controlada no solo. Rio de Janeiro: ABES/ PROSAB, 1999. p.29-52.

HAANDEL, A.C. Van; LETTINGA, G. Tratamento anaeróbio de esgotos: um manual para regiões de clima quente. Campina Grande: Epgraf, 1994. 199 p. 
JAVAREZ JÚNIOR, A. Avaliação de um sistema de tratamento e uso agrícola de esgoto sanitário. 2005. 99 f. Tese (Doutorado em Água e Solo) - Faculdade de Engenharia Agrícola, Universidade Estadual de Campinas, Campinas, 2005.

JAVAREZ JÚNIOR, A.; PAULA JÚNIOR, D.R. Implantação e avaliação preliminar de sistema integrado de tratamento e reúso agrícola de esgoto (SITRAE). In: CONGRESSO DO CONE SUL DA AIDIS, 4., 2003, São Paulo. Anais... São Paulo: Associação Brasileira de Engenharia Sanitária e Ambiental, 2003. p.1-8.

MAZZOLA, M. Uso de leitos cultivados de fluxo vertical por batelada no pós-tratamento de efluente de reator anaeróbio compartimentado. 2003. 99 f. Dissertação (Mestrado em Água e Solo) - Faculdade de Engenharia Agrícola, Universidade Estadual de Campinas, Campinas, 2003.

MORAIS, J.C.de; KATO, M.T.; FLORENCIO, L.T. Avaliação de um sistema UASB para tratamento de esgotos domésticos em Jaboatão dos Guararapes, Pernambuco. In: CONGRESSO BRASILEIRO DE ENGENHARIA SANITÁRIA E AMBIENTAL, 21., 2001, João Pessoa. Anais... Associação Brasileira de Engenharia Sanitária e Ambiental, 2001. p.1-5.

PAULA JÚNIOR, D.R.; JAVAREZ JÚNIOR, A.; VALENTIN, M.A.A.; ROSTON, D.M. Implantação de sistema modular para tratamento, disposição e reúso agrícola de esgotos de comunidades rurais. In: CONGRESSO BRASILEIRO DE ENGENHARIA AGRÍCOLA, 29., 2000, Fortaleza. Anais... Fortaleza: Sociedade Brasileira de Engenharia Agrícola, 2000. 1 CD-ROM.

SPERLING, M. Von. Princípios do tratamento biológico de águas residuárias. Introdução à qualidade das águas e ao tratamento de esgotos. Belo Horizonte: Departamento de Engenharia Sanitária e Ambiental - UFMG, 1995. v.1, 240 p.

VALENTIM, M.A.A. Uso de leitos cultivados no tratamento de efluente de tanque séptico modificado. 1999. 119 f. Dissertação (Mestrado em Água e Solo) - Faculdade de Engenharia Agrícola, Universidade Estadual de Campinas, Campinas, 1999. 